\title{
The impact of climate change and aquatic salinization on mangrove species in the Bangladesh Sundarbans
}

\author{
Susmita Dasgupta, Istiak Sobhan, David Wheeler
}

Received: 5 August 2016/Revised: 31 October 2016/Accepted: 22 November 2016/Published online: 3 May 2017

\begin{abstract}
This paper investigates the possible impacts of climate change on aquatic salinity and mangrove species in the Bangladesh Sundarbans. The impact analysis combines the salinity tolerance ranges of predominant mangrove species with aquatic salinity measures in 27 scenarios of climate change by 2050 . The estimates indicate significant overall losses for Heritiera fomes; substantial gains for Excoecaria agallocha; modest changes for Avicennia alba, A. marina, A. officinalis, Ceriops decandra, and Sonneratia apetala; and mixed results for species combinations. Changes in mangrove stocks are likely to change the prospects for forest-based livelihoods. The implications for neighboring communities are assessed by computing changes in high-value mangrove species for the five sub-districts in the Sundarbans. The results of the impact analysis indicate highly varied patterns of gain and loss across the five subdistricts. Overall, however, the results suggest that salinity-induced mangrove migration will have a strongly regressive impact on the value of timber stocks because of the loss of highest value timber species, Heritiera fomes. In addition, the augmented potential for honey production will likely increase conflicts between humans and wildlife in the region.
\end{abstract}

Keywords Aquatic salinization .

Bangladesh: Sundarbans · Climate change $\cdot$ Mangrove

\section{INTRODUCTION}

The Sundarbans is a tidal-wetland forest delta with an approximate area of 10200 sq. km along the Bay of Bengal, spanning coastal segments of Bangladesh and India. It is the largest remaining contiguous mangrove forest in the world, ${ }^{1}$ and one of the richest ecosystems. The region is known for its exceptional biodiversity, which includes 350 species of vascular plants, 250 fish species, 8 amphibians, 58 reptiles, 300 birds, and 42 mammals, along with numerous species of phytoplankton, fungi, bacteria, zooplankton, invertebrates, and mollusks (Gopal and Chauhan 2006). The Sundarbans also harbor numerous threatened species, including the endangered Royal Bengal Tiger, several species of endangered dolphins, a critically endangered river terrapin, the vulnerable estuarine crocodile, Indian flap-shelled turtle, peacock soft-shelled turtle, and the near-threatened Indian python. The Sundarbans is also an important breeding ground for indigenous and marine fish species (e.g., Tenualosa ilisha) and cetaceans such as the Ganges and Irrawady dolphins (GoB 2010). The area is internationally recognized under the Ramsar Convention and is a UNESCO World Heritage site.

The importance of the Sundarbans ecosystem is also associated with its valuable ecological services, including (1) trapping of sediment and land formation; (2) protection of millions of human lives and assets in coastal Bangladesh and West Bengal (India) from cyclones; (3) acting as a breeding ground and nursery for indigenous and marine fish, as well as other aquatic life; (4) production of wood; (5) provision of food and building materials; (6) production of oxygen; (7) recycling of waste; and (8) sequestration of carbon (GoB 2010).

Although the Sundarbans' ecological importance and uniqueness are recognized by Bangladesh, India and the international community, and its conservation is an obligation under international conventions and treaties, the region is currently threatened by a number of natural

\footnotetext{
1 The second largest is only about one-tenth of the Sundarbans' size (Agarwala et al. 2003).
} 
factors and human activities. The area is still in active formation as its rivers change their course. Eastward meandering of the Ganges and Brahmaputra Rivers over time is affecting sedimentation and reducing freshwater inflows significantly. In addition, water supplies, sedimentation, and the region's topography and hydrology have all been affected by human activities, such as construction of upstream dams, embankments to protect land from tides, over-exploitation of mangrove timber, urban and industrial pollution, and mangrove clearing for agriculture and aquaculture. Local human-induced losses will probably continue, and climate change is likely to aggravate current problems.

Climate change poses a number of threats to the mangrove forests, including rise in sea level, rise in air and water temperature, and change in the frequency and intensity of precipitation and storms (Alongi 2008). Among these threats, rise in sea level may even threaten the survival of mangroves if the landward migration of mangroves is obstructed by lack of availability of adequate and suitable space for migration/expansion and the rate of sea-level rise is greater than the rate at which mangroves can migrate (Ellison and Stoddart 1991; Semeniuk 1994; UNEP 1994; McLeod and Salm 2006; Lange et al. 2010). Although historically mangroves have shown considerable resilience to fluctuations in sea level (Alongi 2002; Gilman et al. 2006; Erwin 2009). Their future adaptation may not keep pace with rapid, climate-driven sea level rise for the reasons cited above. The extent of permanent inundation of the Sundarbans from sea level rise is uncertain as it is located in the active Ganges-Brahmaputra delta, where sedimentation is still taking place. For the Sundarbans, however, increased saltwater intrusion from sea level rise and shortage of nutrients from freshwater flows are the greatest challenges in a changing climate (For example, see Karim et al. 1990; SRDI 2000; Peterson and Shireen 2001; IWM 2003; UK DEFR 2007; SRDI 2010; Dasgupta et al. 2015a, b, c). Healthy mangroves need daily fluxes from both ocean and fresher water. The Sundarbans are already facing a serious shortage of freshwater during the dry season (OctoberMay) because some major distributaries of the Ganges feeding the Sundarbans are currently moribund. Anticipated alteration of riverine flows from the Himalayas and an increase in sea level will intensify salinity intrusion as climate change continues. The associated increase in aquatic salinization will inevitably change the hydrological regime of the Sundarbans and alter its forest ecology.

These changes will have significant implications for the present and the future management of the Sundarbans, as well as the forest-based livelihoods of tens of thousands of poor inhabitants. Therefore, understanding the physical and economic effects of salinity diffusion and planning for appropriate adaptation will be critical for management of the Sundarbans, as well as for long-term development and poverty alleviation in adjacent areas. This paper attempts to contribute by assessing the impact of aquatic salinization on the spatial distribution of mangrove species.

The focus of our analysis is on the Bangladesh Sundarbans, ${ }^{2}$ as the potential impact of salinity on the region has become a major concern for the Government of Bangladesh and affiliated research institutions. Recently, the Bangladesh Climate Change Resilience Fund (BCCRF) Management Committee and research conducted by the World Bank (Dasgupta et al. 2014a, b, c, 2016a) have highlighted salinity intrusion as a critical part of adaptation to climate change. Prior research on this issue has been conducted or co-sponsored by the Ministry of Environment and Forests (World Bank 2000) and two affiliated institutions: the Center for Geographic and Environmental Information Services (Hassan and Shah 2006) and the Institute of Water Modeling (IWM 2003; UK DEFR 2007). ${ }^{3}$

This paper attempts to contribute by extending previous work on aquatic salinization and mangrove migration. First, we overlay a digital map of aquatic salinity with the most recent mangrove distribution map of the Bangladesh Sundarbans to develop estimates of the salinity tolerance ranges of mangrove species. Second, we combine projections of future aquatic salinity in the region for 27 scenarios of climate change from recent work by Dasgupta et al. (2015a) with our estimated species salinity tolerance ranges to produce spatial distribution scenarios for mangroves in 2050 .

At the outset, we acknowledge that this paper does not address potential change in the Sundarbans land area by 2050. The Ganges Delta in Bangladesh where Sundarbans is located is still in an active, dynamic state. At present there is an intense controversy in Bangladesh regarding the estimates and projections of erosion, accretion, and land subsidence in the southwest coastal region, including Sundarbans. In light of the widely-varying estimates of erosion, accretion, and subsidence, this paper refrains from any projection of the area of Bangladesh Sundarbans by 2050 .

\footnotetext{
${ }^{2}$ Approximately, $60 \%$ of the Sundarbans is in Bangladesh, covering about $6000 \mathrm{sq} . \mathrm{km}$ in certain districts of Khulna, Satkhira and Bagerhat districts.

${ }^{3}$ Previous research on salinization in coastal Bangladesh has employed a variety of methods (see for example Nobi and Das Gupta 1997; Aerts et al. 2000; IWM 2003; Bhuiyan and Dutta 2011). Many of these studies have simulated salinity change in rivers and estuaries using hydraulic engineering models and have compared the results with actual measures. In the most comprehensive study to date, Dasgupta et al. (2015a) have used 27 climate change scenarios to project salinity trends in coastal rivers to 2050 , with a model that links the spread and intensity of salinity to changes in the sea level, temperature, rainfall, and altered riverine flows from the Himalayas. The study provides new estimates of location-specific river salinity through 2050 .
} 


\section{MATERIALS AND METHODS}

\section{Data}

The spatially disaggregated data used for our analysis are described below:

- Administrative boundaries of 5 sub-districts in the Sundarbans region

Sub-district maps are constructed from an administrative shapefile provided by the Government of Bangladesh. The Sundarbans mangrove forest spans five subdistricts in Khulna Division: Dacope and Koyra in Khulna District; Mongla and Sarankhola in Bagerhat, and Shyamnagar in Satkhira District.

- Mangrove species in Sundarbans

For this analysis, the Department of Forests, Government of Bangladesh provided a high-resolution map of the distribution of Sundarbans mangrove species in 2013. An aerial photo for 1995 was first used as the base data to produce the vegetation map of Sundarbans Reserve Forest in 2012-2013. Forest administration boundaries prepared under the FAO/UNDP assisted Integrated Resource Development of the Sundarbans Reserve Forest Project in 1995 were also used in the 2012-2013 map. Classified IKONOS multispectral images at 1-m resolution were then used to update the (i) land water boundary, (ii) river courses, and (iii) species composition. Field data were used for ground-truthing the images. Three iterations of correction were necessary for synchronizing the original vegetation map with the classified IKONOS data corrected by field information. 1-m pansharpened IKONOS images were classified by the segmentation method. In the first iteration of the segmentation process, water bodies such as river courses and soil-water boundaries were defined and corrected. In subsequent iterations vegetation cover classes were segmented based on texture and spectral reflectance. Approximately 1000 field samples were used to validate the vegetation cover class identified; each field sample was $50 \mathrm{~m} \times 10 \mathrm{~m}$ in size. As a 1997 vegetation map was used for the calibration, no field sample data was necessary to calibrate the classification process.

Although the records indicate that the Sundarbans region includes scattered habitat for 27 tree species, forest inventories conducted at different times have concluded that approximately $99 \%$ of the forest area is predominantly populated by seven mangrove species (see Table 1).

In addition, a significant area of Sundarbans has mixed varieties of mangrove species, with species proportions varying with site conditions. Forest types are generally classified by dominant species (Hussain and Acharya 1994; GoB 2010).
- Current and future aquatic salinity in the southwest Region

The analysis also draws extensively on spatial data from the River Salinity Information System (RSIS), ${ }^{4}$ based on Dasgupta et al. (2015a, b, c). The RSIS presents monitored river salinity in 2012 and quantifies the prospective relationship between climate-induced changes in sea level, temperature, rainfall, and riverine flows from the Himalayas with the spread and intensity of aquatic salinization in the coastal zone. The system incorporates projected land subsidence in the Ganges Delta, as well as alternative levels of upstream freshwater withdrawal in 2050. It provides location-specific estimates of aquatic salinity in December 2011; January-June 2012; December 2049; and January-June 2050. The estimates for 2050 incorporate 27 climate scenarios based on three global emissions scenarios (B1, A1B, A2) ${ }^{5}$ from the IPCC's Fourth Assessment Report (AR4); two estimates of sea level rise by 2050 (27 cm for scenario B1, $32 \mathrm{~cm}$ for A1B and A2); three global circulation models (IPSL-CM4, MIROC3.2, ECHO-G) ${ }^{6}$; and three annual subsidence rates for land in the lower Ganges Delta $\left(2,5\right.$, and $9 \mathrm{~mm} /$ year). ${ }^{7}$

\footnotetext{
${ }^{4}$ http://sdwebx.worldbank.org/climateportal/index.cfm?page=web salinity_dynamics\&ThisRegion $=$ Asia\&ThisCcode $=$ BGD Accessed April 2017.

5 Basic elements of the three scenarios are as follows:

B1: rapid economic growth with convergence among regions; global population that peaks in mid-century and declines thereafter; rapid change in economic structures toward a service and information economy, with reductions in material intensity and the introduction of clean and resource-efficient technologies.

A1B: Rapid economic growth with convergence among regions; global population that peaks in mid-century and declines thereafter; rapid introduction of new and more efficient technologies; energy from mixed fossil and renewable sources.

A2: Non-convergent economic development; continuously increasing population; heterogeneous technologies and energy sources.

${ }^{6}$ Model implementing institutions are as follows:

IPSL-CM4: Institut Pierre Simon Laplace, France;

MIROC3.2: Center for Climate System Research, University of Tokyo, National Institute for Environmental Studies, Japan, Frontier Research Center for Global Change, Japan;

ECHO-G: Meteorological Institute of the University of Bonn, Germany, Model and Data Group, Max Planck Institute for Meteorology, Hamburg, Germany, Korea Meteorological Administration.

7 The Ganges Delta in Bangladesh is still in an active, dynamic state. Therefore, it is critical to include projections of land subsidence of the lower Bengal delta (the Ganges Delta in Bangladesh) in simulating future climate scenarios. Physical impacts of relative mean sea-level rise are caused by a combination of sea-level rise associated with global warming and vertical land movement (subsidence or accretion). At present, there is an intense controversy in Bangladesh over alternative estimates and projections of land subsidence in the coastal region (see Dasgupta et al. 2015a, b, c). In light of the widely varying estimates, the hydrological modeling for our analysis was run for three alternative scenarios of land subsidence: 2,5 , and $9 \mathrm{~mm}$ per year.
} 
Table 1 Bangladesh Sundarbans mangrove species. Source Aziz and Paul (2015)

\begin{tabular}{ll}
\hline Scientific name & Vernacular name \\
\hline Avicennia alba, A. marina, A. officinalis & Baen \\
Excoecaria agallocha & Gewa \\
Ceriops decandra & Goran \\
Bruguiera gymnorrhiza & Kankra \\
Sonneratia apetala & Keora \\
Xylocarpus mekongensis & Passur \\
Heritiera fomes & Sundri \\
\hline
\end{tabular}

Overall, average salinity concentrations of the rivers in the coastal area are higher in the dry season than in the monsoon because of lack of freshwater flow from upstream. Salinity generally increases almost linearly from October (post-monsoon) to late May (pre-monsoon) with the gradual reduction in freshwater flow. At the end of May, the salinity level drops sharply because of rainfall and upstream flow of freshwater through the river system and remains low until early October. Figure 1 presents a high-resolution aquatic salinity map based on salinity estimates for December 2011 and January-June 2012, developed by Dasgupta et al. (2015a). The map exhibits an extremely broad range, from near-marine salinity (27-29 ppt) in southwest Shyamnagar to freshwater (0-1 ppt) in northeast Sarankhola.

Figure 2, on the other hand, illustrates the scale of potential change by combining our 2012 salinity map with the maximum change result for 2050 (AR4 A2 scenario, IPSL global circulation model, $9 \mathrm{~mm} /$ year subsidence in the lower Ganges Delta). Two patterns are particularly striking in Fig. 2. First, higher salinity spreads northward and eastward as the sea level rises, riverine flows change and subsidence continues in the lower Ganges Delta. Second, the transition from 2012 to 2050 is most pronounced in Koyra and northern Shyamnagar.

\section{Methodology}

We conduct our analysis in three steps.

In step (i), GIS software is used to overlay the forest cover map and the administrative boundaries of the $s u b$ districts to understand the current spatial distributions of mangrove species in Sundarbans. The resulting mangrove database identifies 14 mangrove types (species and mixed species) in 8.44 million pixels for the region.

In step (ii), the analysis estimates salinity ranges for the mangrove species, using geographic overlays of mangrove distributions and high-resolution aquatic salinity maps for 2012.

We assign each mangrove pixel to the nearest salinity pixel, calculate total pixels for each integer salinity value and mangrove type, and use the totals to compute incidence probabilities for mangrove types across salinity values. We drop marginal occurrences beyond the 90th percentile to ensure robust projections.

In step (iii), projections of location-specific aquatic salinity for alternative climate change scenarios are used to predict impacts of salinization on mangrove species by 2050. For each of the 8.44 million pixels $^{8}$ in our map, we identify candidate mangrove types whose salinity tolerance range includes the pixel's projected salinity in 2050 . We assume that the currently-resident species will continue occupying the pixel if projected salinity remains within its incidence range. Where this is not the case, we select transition-appropriate candidate species with the highest likelihood score: incidence probability for the pixel's projected salinity, divided by the distance to the candidate species' nearest habitat in 2013. The likelihood score incorporates two predictive factors: a species' current locational intensity at the pixel's projected salinity, and the species' proximity to the pixel, which proxies its conformity with unobserved local conditions in the pixel's neighborhood. We have tested three weighting methodologies for this exercise: linear distance, distance squared (which gives more weight to proximity), and the square root of distance (which gives less weight). The spatial projection results are effectively identical in all cases, so we confine our presentation to the results for linear distance. The other results are available from the authors on request.

To illustrate the relevance of distance, consider species A and B that have identical incidence probabilities for a pixel's projected salinity. Species A has current habitat within $5 \mathrm{~km}$ of the pixel, while the closest habitat for B is $200 \mathrm{~km}$ away. This disparity suggests that unobserved local conditions favor A. Absence of information did not allow our methodology to directly consider potential hydrologic connectivity of aquifers upstream and downstream in the likelihood score. We also use historical and scientific information to select transition-appropriate species for particular cases.

\section{RESULTS}

\section{Mangrove species in the Sundarbans}

In order to understand the geographic distribution of the various mangrove species, we start with a geographic overlay of the Bangladesh Sundarbans forest with $s u b$ -

\footnotetext{
${ }_{8}^{8}$ We use pixels for numerical convenience; pixel numbers are readily translated to areas. In our mapping system, one pixel has a side length of approximately $55 \mathrm{~m}$ and an area of approximately 0.3 ha.
} 

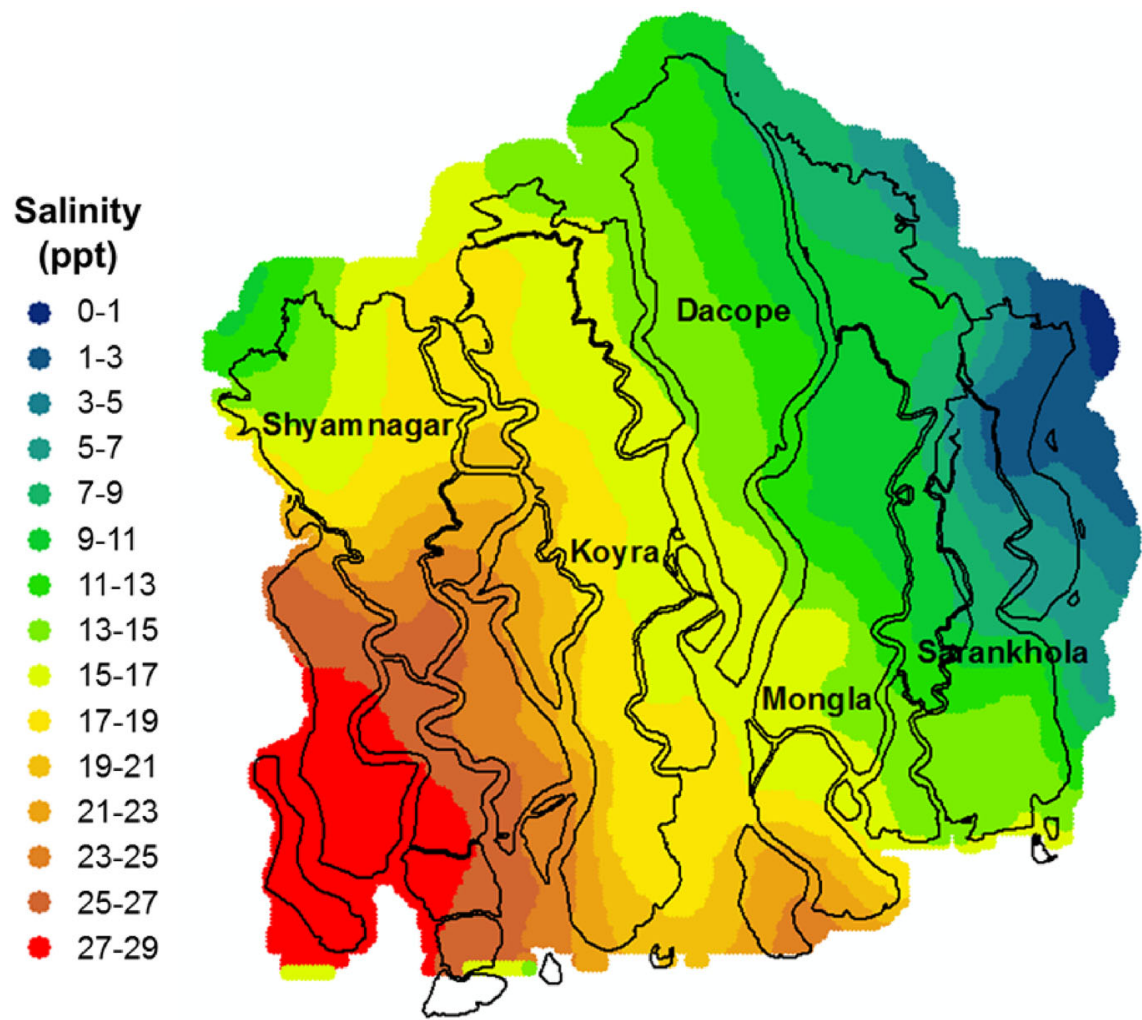

Fig. 1 Sundarbans region: estimated aquatic salinity, 2012

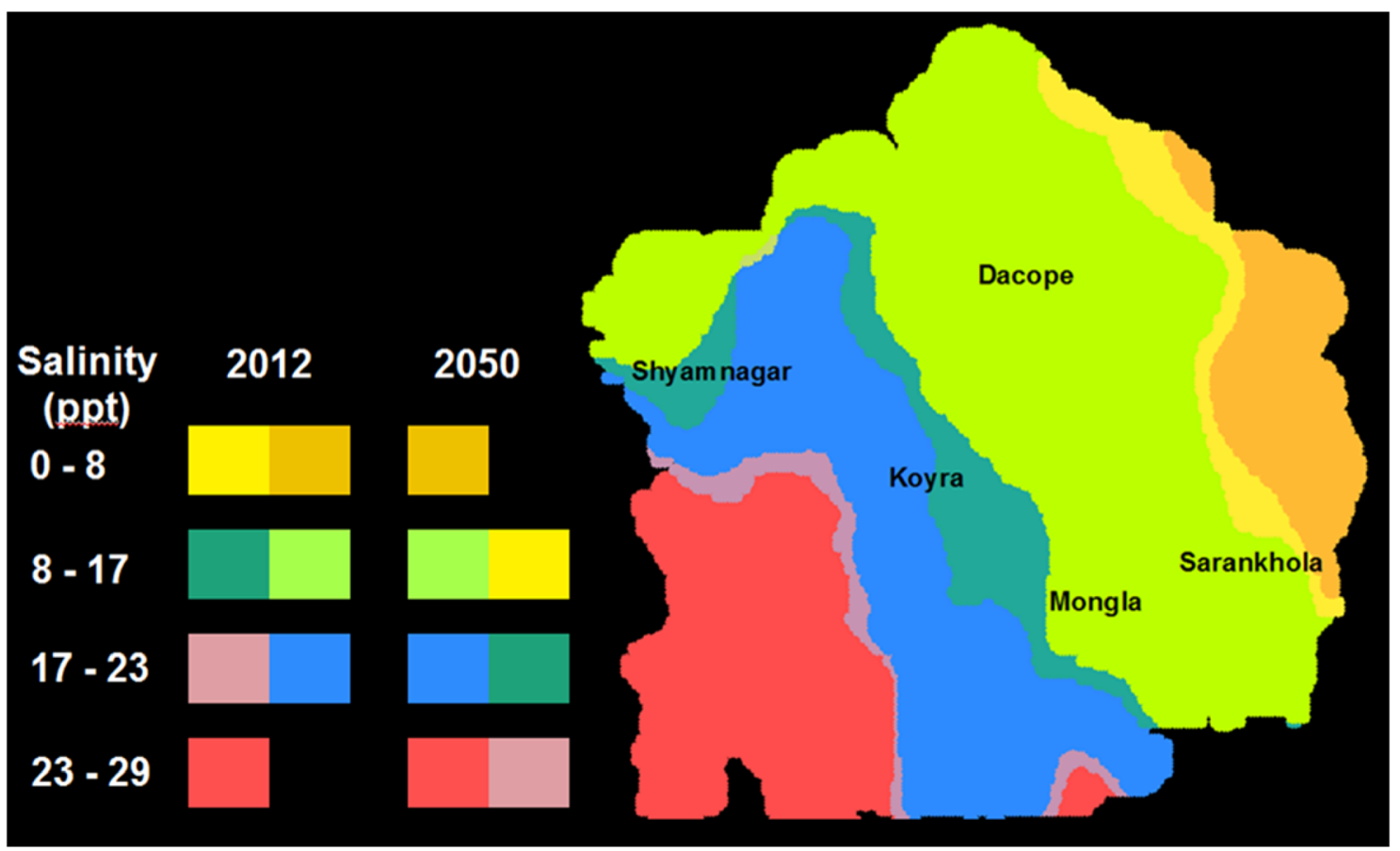

Fig. 2 Salinity ranges, 2012 and 2050 (AR4 A2, GCM IPSL, subsidence $9 \mathrm{~mm} /$ year). Note In this figure, color-coded rows in the legend identify salinity ranges in 2012 and 2050. The first row shows that in 2012, salinity in the range 0-8 ppt characterizes the areas colored tan and brown in the eastern region. By 2050, advancing salinity shrinks the 0-8 ppt range to the brown region alone. In a similar vein, salinity in the range $8-17$ ppt is found in the areas colored dark and light green in 2012. By 2050, increasing salinity causes an eastward shift of this salinity range. The western (dark green) part moves up to the range 17-23 ppt, while the tan area in the east (previously in the range 0-8 ppt) moves into the range $8-17 \mathrm{ppt}$ 
district maps constructed from an administrative shapefile provided by the Government of Bangladesh. As mentioned in "Data" section, the Sundarbans mangrove region includes five sub-districts in Khulna Division: Dacope and Koyra in Khulna District; Mongla and Sarankhola in Bagerhat; and Shyamnagar in Satkhira. Figure 3 displays a high-resolution map of the distributions of 14 Sundarbans mangrove types (species and mixed species) in 2013. The map reveals concentrations of Ceriops decandra (Goran) in southern and western Shyamnagar; Excoecaria agallocha (Gewa) in eastern Shyamnagar, western Koyra, and southern Mongla; and Heritiera fomes (Sundri) in Koyra, Dacope, and northern Mongla. Between these areas of concentration lie mixed patterns dominated by the first species entries in the legend of Fig. 3.

Notable mixes include Ceriops decandra (Goran)—Excoecaria agallocha (Gewa) and Excoecaria agallocha (Gewa)_Ceriops decandra (Goran) in most of Shyamnagar, and Excoecaria agallocha (Gewa)_Heritiera fomes (Sundri) and Heritiera fomes (Sundri)_Excoecaria agallocha (Gewa) in northeast Shyamnagar and northwest Koyra. Figure 4 displays species shares by sub-district as an aid to identifying clusters for individual species. Avicennia alba, A. marina, A. officinalis (Baen) is concentrated in Dacope (51.1\%), Excoecaria agallocha (Gewa) in Mongla (52.9\%), Ceriops decandra (Goran) in Shyamnagar $(97.7 \%)$, and Sonneratia apetala (Keora) in Koyra and Mongla (28.7 and 35.7\%, respectively). Heritiera fomes (Sundri), the most valuable species, is relatively evenly spread across Dacope (33.6\%), Koyra (32.7\%), and Mongla $(26.7 \%)$.

Our findings are in general agreement with the salinity tolerances of mangrove species documented in the report of the IUCN Wetlands Programme (Hussain and Acharya 1994) and the forest inventory of the Bangladesh Sundarbans (Chaffey et al. 1985).

\section{Estimation of salinity ranges for mangrove species}

To determine salinity tolerance ranges for mangrove species and mixes, we combine the mangrove distribution data illustrated in Fig. 3 with the high-resolution aquatic salinity maps for December 2011-June 2012 that underlie Fig. 1. Visual inspection of geographic overlays reveals a broad spatial correlation pattern in Shyamnagar, Koyra, and Dacope: apparent domination for Ceriops decandra (Goran) in the salinity range 23-29 ppt, Excoecaria agallocha (Gewa) mixes with Ceriops decandra (Goran) and Heritiera fomes (Sundri) in 17-21, and Heritiera fomes (Sundri) in 11-17.

Although these observations provide a useful overview, our high-resolution information permits more precise estimation of salinity tolerance ranges.
Table 2 corroborates the previous observations about mangrove spatial distributions, while providing much more detail about the relative incidence of mangrove species across salinity intervals. Among individual species, clustering is pronounced for Avicennia alba, A. marina, A. officinalis (Baen) (in the salinity range 12-14 ppt), Excoecaria agallocha (Gewa) (14-16), Ceriops decandra (Goran) (27-28), and Heritiera fomes (Sundri) (14-17), while Sonneratia apetala (Keora) is more evenly distributed across a broad salinity range. Salinity ranges for mixed groups reflect the ranges of their constituent species [e.g., Excoecaria agallocha (Gewa)-Ceriops decandra (Goran) and Ceriops decandra (Goran)_Excoecaria agallocha (Gewa); Excoecaria agallocha (Gewa)-Heritiera fomes (Sundri); and Heritiera fomes (Sundri)-Excoecaria agallocha (Gewa)].

The critical building blocks of our analysis are estimated salinity tolerance ranges and clustering patterns within those ranges for 14 mangrove species and species mixes derived from the high-resolution digital maps of aquatic salinity and mangroves (Table 2).

\section{Projections of mangrove species migration through 2050}

Finally, we estimate the effects of salinization on mangrove migration by combining the estimates of salinity tolerance ranges in Table 2 with 27 aquatic salinity scenarios developed by Dasgupta et al. (2015a).

As mentioned before, we also use historical and scientific information to select transition-appropriate species for particular cases. For example, Sonneratia apetala (Keora) is known to colonize only mudflats in newly emergent areas, but all of our scenarios incorporate some measure of subsidence. We therefore delete Sonneratia apetala (Keora) from the list of transition candidates. We assume that Sonneratia apetala (Keora) remains in its currently inhabited pixels if their projected salinity falls within Sonneratia apetala (Keora)'s incidence range; elsewhere it is replaced by appropriate transition candidates. We eliminate transition candidacy for Excoecaria agallocha (Gewa)-Mathal (coppice), which presents a special case historically. This vegetation type emerged in previously exploited areas, as Excoecaria agallocha (Gewa) mangroves were harvested for paper mills and coppices were regenerated from the root stock. Such harvesting no longer occurs, so future stands of Excoecaria agallocha (Gewa)Mathal (coppice) will only reflect current stands, minus areas where it is replaced by other species because projected salinity exceeds its upper incidence limit.

We rely on prior knowledge of transition dynamics to modify lists of potential replacements for three mangrove types: Heritiera fomes (Sundri), Heritiera fomes (Sundri)- 
- 1 Baen

- 2 Gewa

- 3 Gewa Goran

4 Gewa Mathal (Coppice)

- 5 Gewa Sundri

- 6 Goran

- 7 Goran Gewa

- 8 Keora

- 9 Passur Kankra

- 10 Passur Kankra Baen

- 11 Sundri

- 12 Sundri Gewa

- 13 Sundri Passur

- 14 Sundri Passur Kankra

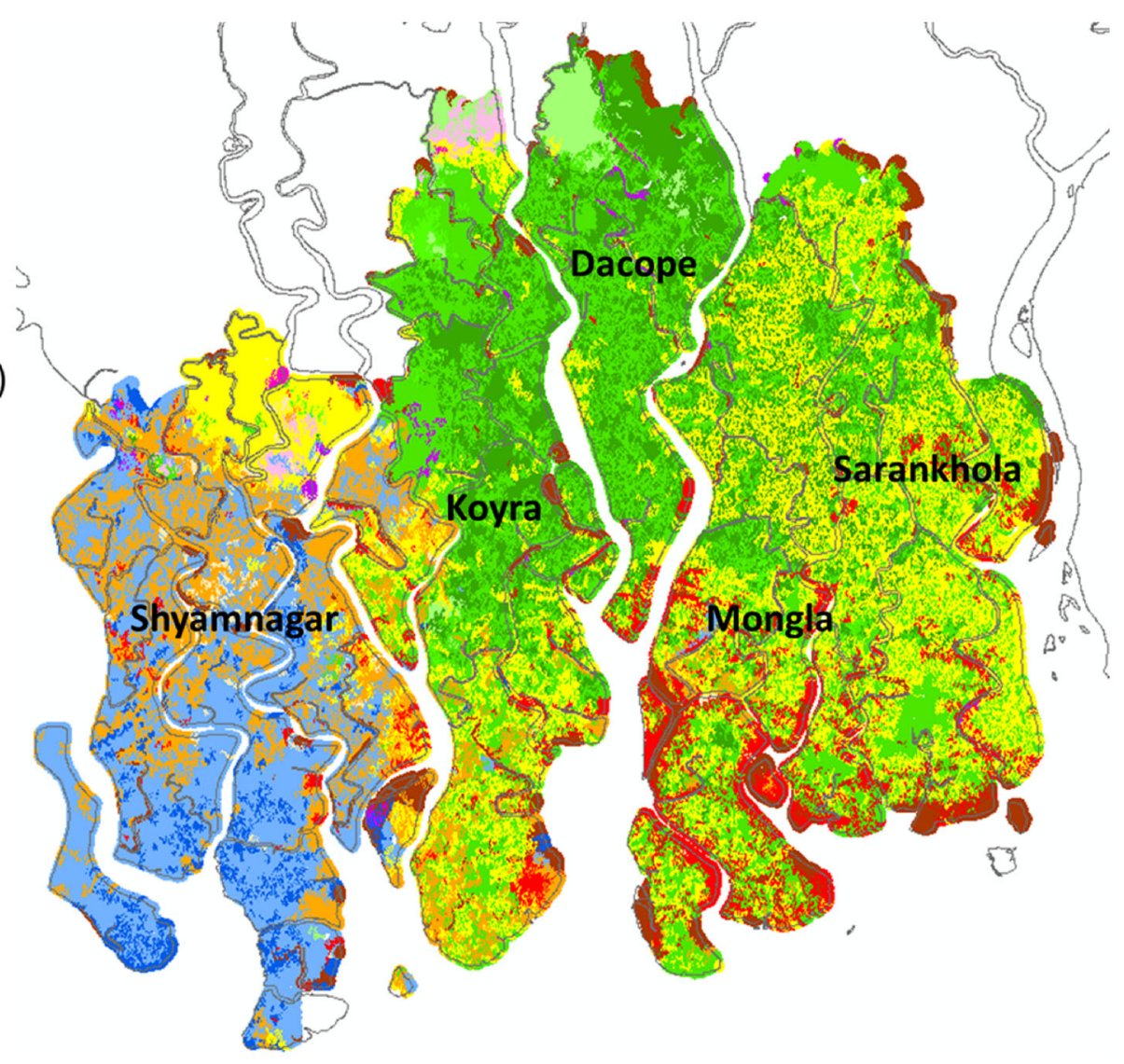

Fig. 3 Mangrove species distribution, 2013

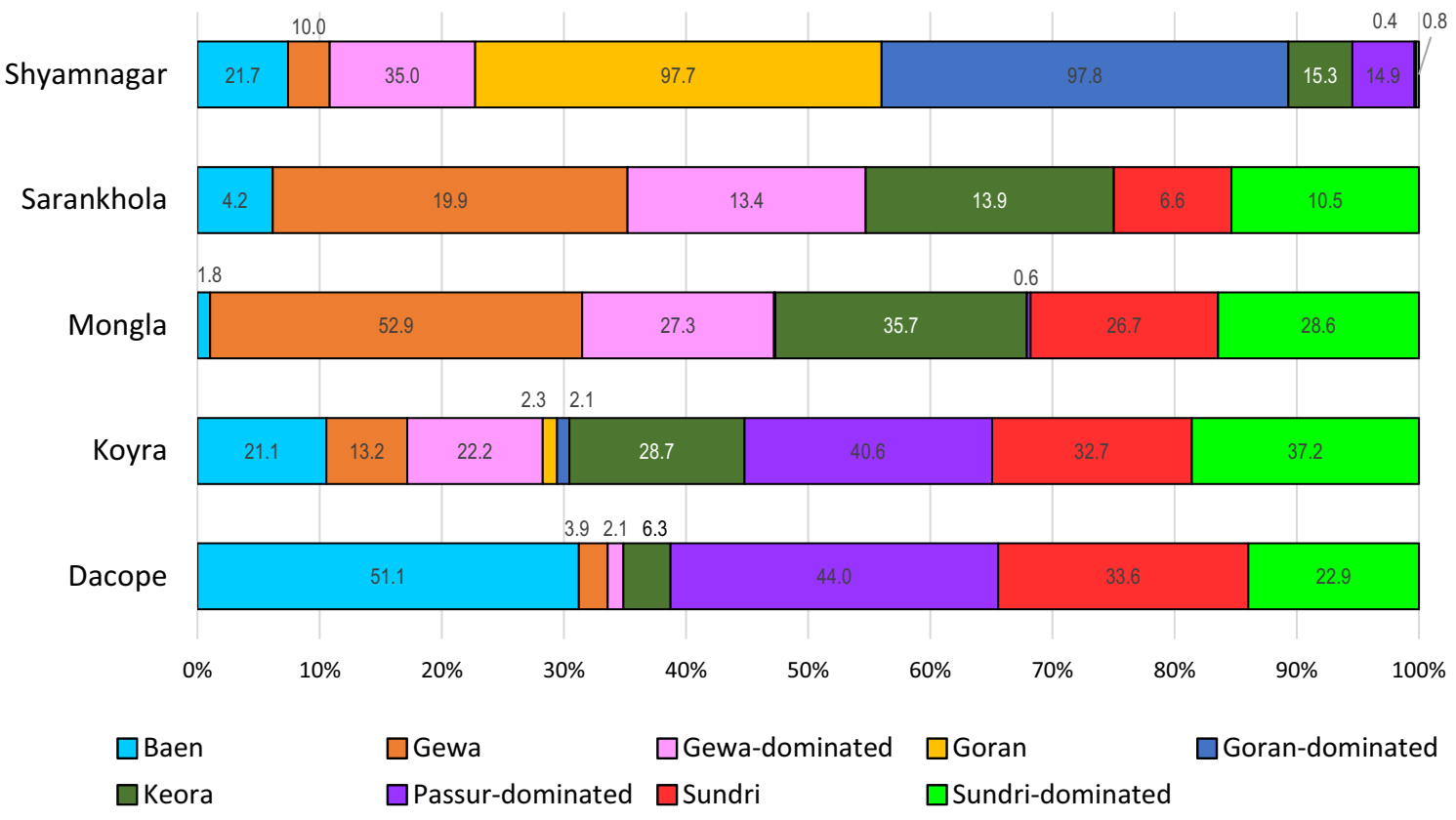

Fig. 4 Distribution of mangrove species by sub-district 
Table 2 Sundarbans mangroves: estimated incidence by salinity interval

\begin{tabular}{|c|c|c|c|c|c|c|c|c|c|c|c|c|c|c|c|}
\hline $\begin{array}{l}\text { Salinity } \\
\text { (ppt) }\end{array}$ & $\begin{array}{l}\% \text { of } \\
\text { total } \\
\text { area }\end{array}$ & Baen & Gewa & $\begin{array}{l}\text { Gewa } \\
\text { Goran }\end{array}$ & $\begin{array}{l}\text { Gewa } \\
\text { Mathal }\end{array}$ & $\begin{array}{l}\text { Gewa } \\
\text { Sundri }\end{array}$ & Goran & $\begin{array}{l}\text { Goran } \\
\text { Gewa }\end{array}$ & Keora & $\begin{array}{l}\text { Passur } \\
\text { Kankra }\end{array}$ & $\begin{array}{l}\text { Passur } \\
\text { Kankra } \\
\text { Baen }\end{array}$ & Sundri & $\begin{array}{l}\text { Sundri } \\
\text { Gewa }\end{array}$ & $\begin{array}{l}\text { Sundri } \\
\text { Passur }\end{array}$ & $\begin{array}{l}\text { Sundri } \\
\text { Passur } \\
\text { Kankra }\end{array}$ \\
\hline 3 & 0.07 & 0 & 0 & 0 & 0 & 0.23 & 0 & 0 & 0.37 & 0 & 0 & 0.90 & 0.22 & 0 & 0 \\
\hline 4 & 0.38 & 0 & 0 & 0 & 0 & 0.98 & 0 & 0 & 0.02 & 0 & 0 & 1.33 & 0.69 & 0 & 0 \\
\hline 5 & 0.55 & 0 & 0 & 0 & 0 & 1.66 & 0 & 0 & 0.48 & 0 & 0 & 1.03 & 0.72 & 0 & 0 \\
\hline 6 & 0.75 & 0 & 3.07 & 0 & 0 & 1.61 & 0 & 0 & 1.23 & 0 & 0 & 1.03 & 0.92 & 0 & 0 \\
\hline 7 & 0.79 & 0 & 2.46 & 0 & 0 & 1.72 & 0 & 0 & 0.72 & 0 & 0 & 0.58 & 0.91 & 0 & 0 \\
\hline 8 & 0.92 & 0 & 1.40 & 0 & 0 & 2.77 & 0 & 0 & 0.72 & 0 & 0 & 0.99 & 1.07 & 0 & 0 \\
\hline 9 & 1.28 & 1.12 & 0.52 & 0 & 0 & 5.60 & 0 & 0 & 4.37 & 0 & 0 & 3.80 & 3.79 & 0.20 & 0 \\
\hline 10 & 3.93 & 0.53 & 0.93 & 0 & 0 & 8.52 & 0 & 0 & 2.37 & 5.44 & 0 & 7.89 & 3.53 & 0.83 & 0 \\
\hline 11 & 3.24 & 0.17 & 1.22 & 0 & 0 & 6.72 & 0 & 0 & 2.77 & 0 & 0 & 9.80 & 2.96 & 1.54 & 3.18 \\
\hline 12 & 3.3 & 12.34 & 1.65 & 0 & 0 & 4.36 & 0 & 0 & 3.54 & 9.07 & 0 & 9.11 & 3.88 & 3.43 & 6.45 \\
\hline 13 & 3.38 & 25.59 & 3.30 & 0.19 & 0 & 5.05 & 0 & 0 & 3.60 & 11.68 & 0 & 6.40 & 5.09 & 0.84 & 41.22 \\
\hline 14 & 5.69 & 16.13 & 10.42 & 0.24 & 0 & 6.94 & 0 & 0 & 8.07 & 6.46 & 0.49 & 10.05 & 13.39 & 1.82 & 21.29 \\
\hline 15 & 7.37 & 5.61 & 15.16 & 2.25 & 2.03 & 9.23 & 1.05 & 0.32 & 8.21 & 1.81 & 44.75 & 11.53 & 17.62 & 10.21 & 5.26 \\
\hline 16 & 8.97 & 2.06 & 14.47 & 0.63 & 0.29 & 4.62 & 0.09 & 0.49 & 12.56 & 19.39 & 17.57 & 12.76 & 11.41 & 64.95 & 16.79 \\
\hline 17 & 6.3 & 1.59 & 6.45 & 0.89 & 0 & 5.46 & 1.66 & 0.37 & 5.06 & 0 & 0 & 14.83 & 9.69 & 3.00 & 0 \\
\hline 18 & 4.97 & 5.58 & 5.42 & 3.24 & 0.68 & 5.66 & 1.89 & 0.84 & 7.34 & 0 & 0 & 0 & 7.39 & 2.02 & 0 \\
\hline 19 & 5.38 & 8.54 & 6.55 & 5.37 & 0.20 & 6.54 & 0.38 & 0.65 & 4.03 & 1.81 & 0 & 0 & 5.74 & 3.99 & 0 \\
\hline 20 & 3.83 & 9.61 & 4.79 & 5.88 & 3.47 & 5.97 & 0.69 & 0.77 & 3.89 & 41.5 & 4.38 & 0 & 3.20 & 0 & 0 \\
\hline 21 & 3.64 & 2.43 & 5.19 & 6.73 & 5.91 & 5.75 & 0.68 & 1.41 & 4.82 & 0 & 8.74 & 0 & 0 & 0 & 0 \\
\hline 22 & 3.48 & 0 & 5.92 & 7.21 & 2.10 & 4.70 & 0.62 & 1.48 & 6.77 & 0 & 7.61 & 0 & 0 & 0 & 0 \\
\hline 23 & 3.5 & 0 & 5.14 & 8.66 & 4.98 & 0 & 0.54 & 3.34 & 4.48 & 0 & 11.37 & 0 & 0 & 0 & 0 \\
\hline 24 & 3.69 & 0 & $\mathbf{0}$ & 10.52 & 5.64 & 0 & 2.36 & 6.83 & 2.56 & 0 & 0 & 0 & 0 & 0 & 0 \\
\hline 25 & 3.09 & 0 & $\mathbf{0}$ & 9.25 & 19.01 & 0 & 10.33 & 10.02 & 3.93 & 0 & 0 & 0 & 0 & 0 & 0 \\
\hline 26 & 3.44 & 0 & $\mathbf{0}$ & 12.35 & 36.16 & 0 & 3.45 & 8.99 & 0 & 0 & 0 & 0 & 0 & 0 & 0 \\
\hline 27 & 4.94 & 0 & 0 & 15.53 & 18.08 & 0 & 29.91 & 31.69 & 0 & 0 & 0 & 0 & 0 & 0 & 0 \\
\hline 28 & 13.10 & 0 & 0 & 11.06 & 0 & 0 & 46.36 & 32.79 & 0 & 0 & 0 & 0 & 0 & 0 & 0 \\
\hline
\end{tabular}

Bold values indicate the key focal species for our analysis. The column for each species records the percent of its range that is observed at each salinity measure

Xylocarpus mekongensis (Passur), and Heritiera fomes (Sundri)_Xylocarpus mekongensis (Passur)—Bruguiera gymnorrhiza (Kankra). None of these types is likely to be replaced directly by Excoecaria agallocha (Gewa)-Ceriops decandra (Goran), Ceriops decandra (Goran), or Ceriops decandra (Goran)—Excoecaria agallocha (Gewa), and we have pruned potential replacement lists accordingly.

\section{Illustrative projection results}

Figure 5 illustrates our projection results using the maximal case (AR4 A2, GCM IPSL, subsidence $9 \mathrm{~mm} /$ year) because it provides the clearest view of potential change. Comparison of Fig. 5 with Fig. 3 provides a useful overview of progressive salinization's impacts on the most populous mangrove types. Ceriops decandra (Goran) and Ceriops decandra (Goran)Excoecaria agallocha (Gewa) advance to the north and east in
Shyamnagar; Excoecaria agallocha (Gewa), Excoecaria agallocha (Gewa)-Ceriops decandra (Goran) and Excoecaria agallocha (Gewa)-Heritiera fomes (Sundri) shift eastward in Koyra and expand in southern Mongla; Heritiera fomes (Sundri) retreats almost entirely from central and western Koyra, replaced mostly by Heritiera fomes (Sundri) Excoecaria agallocha (Gewa) in areas not newly dominated by Excoecaria agallocha (Gewa)_Heritiera fomes (Sundri).

\section{General assessment of mangrove projections}

We generalize our results by projecting the distribution of mangrove types for all 27 scenarios. Table 3 is sorted in ascending order by percent change for Heritiera fomes (Sundri), the most valuable species. All scenarios project declines for Heritiera fomes (Sundri), ranging from 24.2 to $12.1 \%$. The declines are generally largest for $9 \mathrm{~mm} / \mathrm{year}$ subsidence, followed successively by 5 and $2 \mathrm{~mm} /$ year. We 


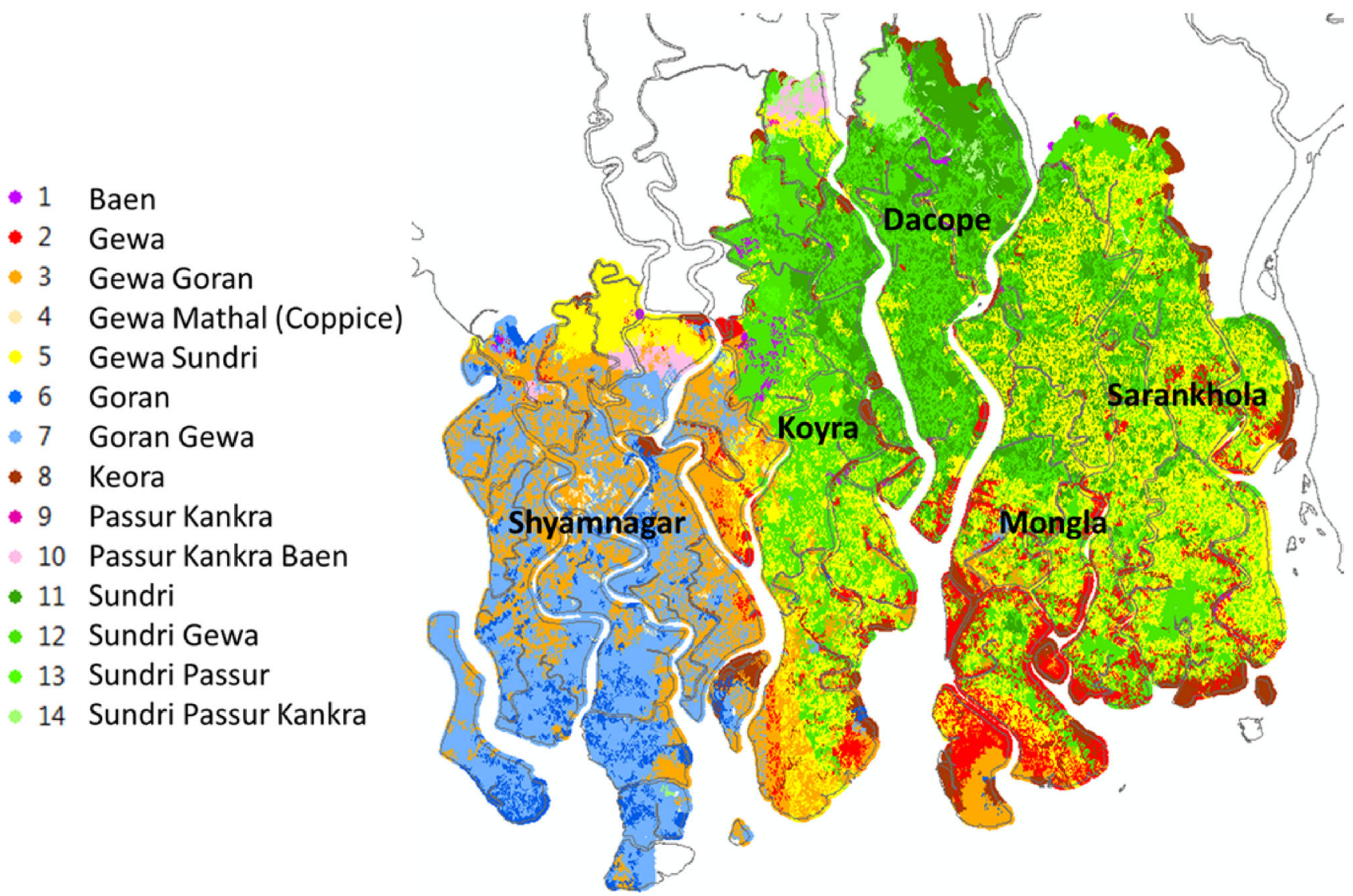

Fig. 5 Mangrove distributions, 2050

also find large declines for Xylocarpus mekongensis (Passur)—Bruguiera gymnorrhiza (Kankra) (from 45.1 to 8.0\%) and large increases for Excoecaria agallocha (Gewa) (19.8 to 23.0\%), Excoecaria agallocha (Gewa)-Ceriops decandra (Goran) (13.3 to 22.5\%) and Xylocarpus mekongensis (Passur)_Bruguiera gymnorrhiza (Kankra)_Avicennia alba, A. marina, A. officinalis (Baen) (33.1 to 51.7\%), while projected increases are significantly smaller for Ceriops decandra (Goran) and Ceriops decandra (Goran) - Excoecaria agallocha (Gewa). Our projections for Heritiera fomes (Sundri) and Ceriops decandra (Goran) are in general agreement with estimated changes by Blasco and Aizpuru (2002), Potkin (2004), and Hoque et al. (2006).

It should be noted that Mukhopadhyay et al. (2015) projected future mangrove distributions from recent trends in mangrove migration using an approach based on a Markov chain model and cellular automata. Our approach differs significantly, because we project alternative futures by combining empirical estimates of mangrove species' salinity tolerance ranges with salinity projections developed from several IPCC AR4 climate scenarios, global circulation model projections, and models of riverine flow and land subsidence in the lower Ganges Delta.

\section{DISCUSSION}

The Sundarbans contributes significantly to both the economy of southwestern Bangladesh and the national economy (Potkin 2004), and forest-based livelihoods are important in the region. Historically, the Sundarbans have provided important supplies of timber, pulp, firewood, reeds, Nypa fruticans, Phoenix Fronds, honey, bee wax, fish, crab, and shrimp (Gopal and Cahuhan 2006; IPAC 2010; Uddin et al. 2013). In 1989, the Forest Department imposed a moratorium on the felling of trees and collection of firewood. Although the ban on felling trees in the Sundarbans is likely to remain, estimated Annual Allowable Cuts ranging from $54000 \mathrm{~m}^{3}$ to approximately $143000 \mathrm{~m}^{3}$ of Sundri were reported in the Integrated Resource Management Plan of the Forest Department of Government of Bangladesh in 2010 (GoB 2010). The remaining timber of Sundarbans has significant potential value. For example, the estimated price of Sundri-equivalent-timber BDT $41890 / \mathrm{m}^{3}$, and the price of other species is BDT $2375 / \mathrm{m}^{3}$ (Data Source: Economic and Financial Analysis of the Ganges Barrages Study Project). Our projections indicate that salinization will further deplete the stock of Heritiera 
言

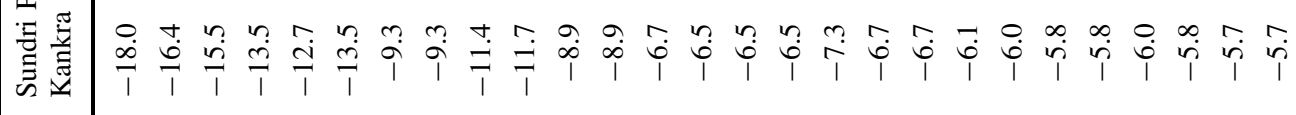

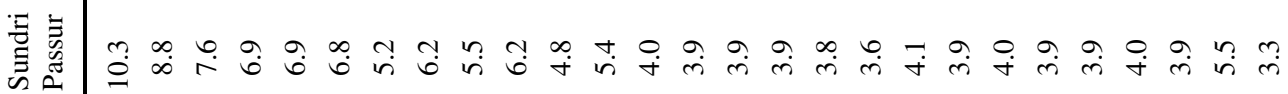

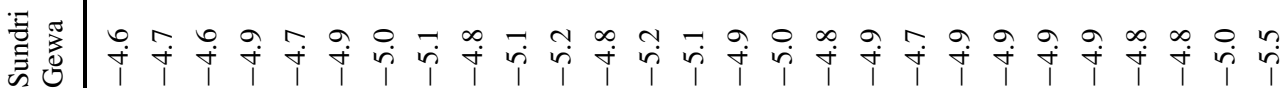
을

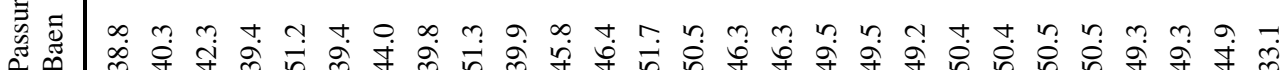

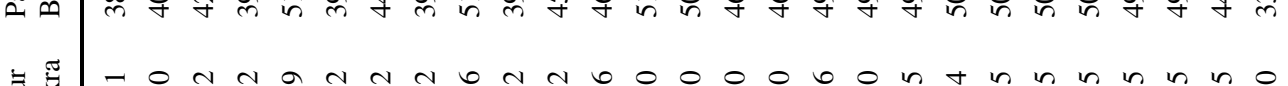

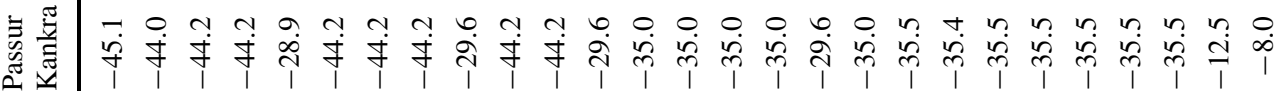

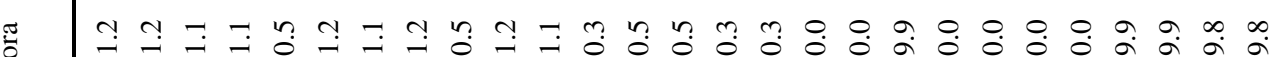

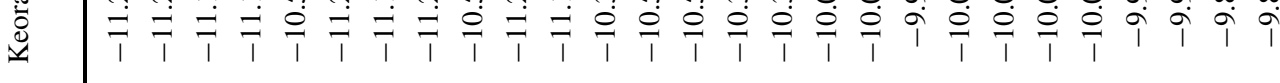
馬

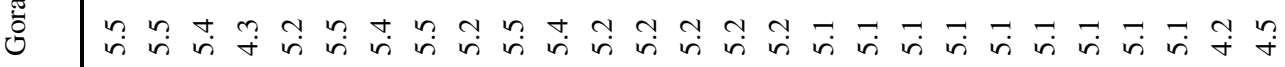

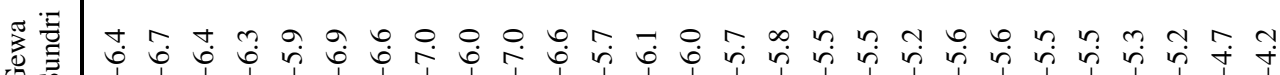
0 क 즌

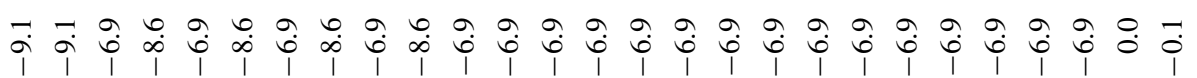

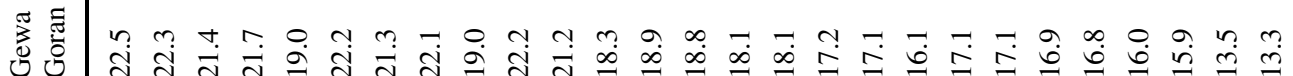
|

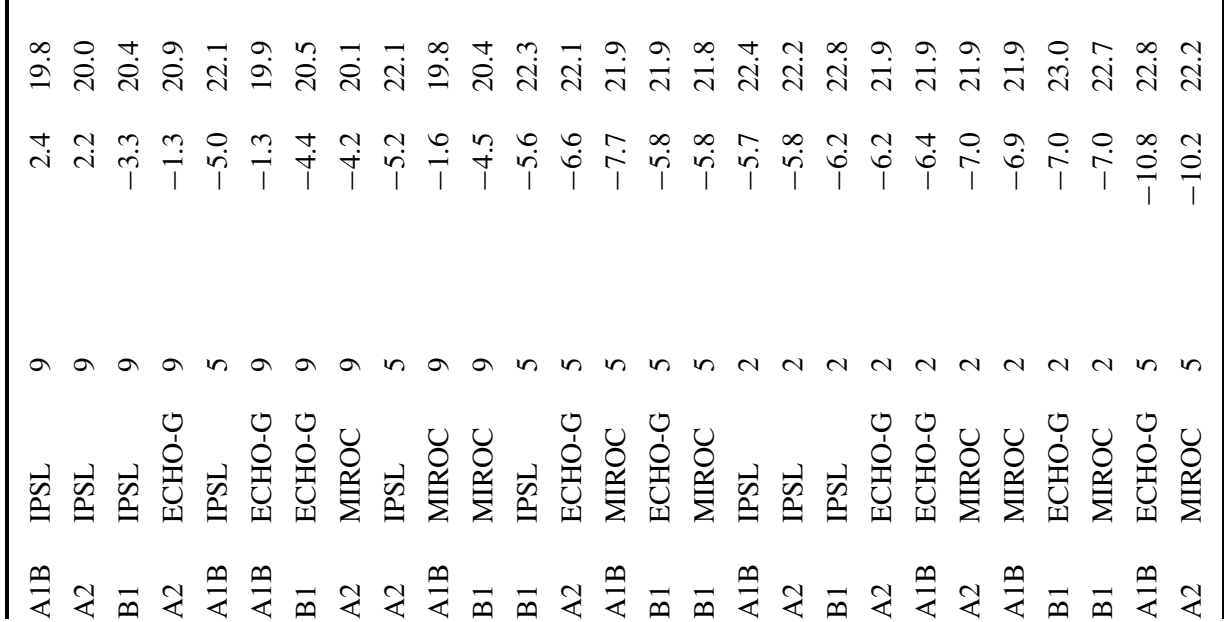


Table 4 Poverty status of the sub-districts and median changes in key mangrove species by sub-district, 27 scenarios

\begin{tabular}{|c|c|c|c|c|c|c|c|c|c|c|}
\hline \multirow[t]{2}{*}{ Sub-district } & \multicolumn{5}{|c|}{ Population and poverty status } & \multicolumn{5}{|l|}{ Median $\%$ change } \\
\hline & $\begin{array}{l}\text { Total } \\
\text { population } \\
(' 000)\end{array}$ & $\begin{array}{l}\text { Poor }^{1} \\
\text { population } \\
\left({ }^{\prime} 000\right)\end{array}$ & $\begin{array}{l}\% \\
\text { Poor }\end{array}$ & $\begin{array}{l}\text { Extreme } \\
\text { poor }^{2} \\
\text { population } \\
\left({ }^{\prime} 000\right)\end{array}$ & $\begin{array}{l}\% \text { Extreme } \\
\text { poor }\end{array}$ & $\begin{array}{l}\text { Avicennia alba, } \\
\text { A. marina, } \\
\text { A. officinalis (Baen) }\end{array}$ & $\begin{array}{l}\text { Excoecaria } \\
\text { agallocha } \\
\text { (Gewa) }\end{array}$ & $\begin{array}{l}\text { Ceriops } \\
\text { decandra } \\
\text { (Goran) }\end{array}$ & $\begin{array}{l}\text { Sonneratia } \\
\text { apetala } \\
\text { (Keora) }\end{array}$ & $\begin{array}{l}\text { Heritiera } \\
\text { fomes } \\
\text { (Sundri) }\end{array}$ \\
\hline Dacope & 152.4 & 67.8 & 44.5 & 37.9 & 24.9 & 0 & 0 & 0 & 0 & 0 \\
\hline Koyra & 193.9 & 95.2 & 49.1 & 56.4 & 29.1 & 45.6 & 20.0 & 20.0 & -0.3 & -58.0 \\
\hline Mongla & 136.5 & 57.2 & 41.9 & 31.0 & 22.7 & 0 & 47.4 & a & 0 & -2.3 \\
\hline Sarankhola & 119.2 & 57.2 & 48.0 & 33.6 & 28.2 & 0 & 0 & 0 & 0 & 0 \\
\hline Shyamnagar & 318.3 & 159.8 & 50.2 & 107.6 & 33.8 & -71.0 & -67.3 & 4.2 & -68.1 & 0 \\
\hline
\end{tabular}

${ }^{a}$ Ceriops decandra (Goran) has an extremely small median increase in Mongla, where the species has a tiny presence in 2013. This would translate to a huge but misleading percent increase

${ }^{1}$ Population with food expenditures at or below the food poverty line established by the Bangladesh Bureau of Statistics. Estimates are from the upper poverty line of the poverty map constructed by the Bangladesh Bureau of Statistics, World food Programme and World Bank (World Bank 2014)

${ }^{2}$ Population with total expenditures at or below the food poverty line established by the Bangladesh Bureau of Statistics. Estimates are from the lower poverty line of the poverty map constructed by the Bangladesh Bureau of Statistics, World food Programme and World Bank (World Bank 2014)

fomes (Sundri), the most valuable species, and will have significant implications for the value of forest resources. ${ }^{9}$

A recent poverty map constructed by the Bangladesh Bureau of Statistics, World Food Programme and World Bank estimates that 437200 residents of these five subdistricts are poor, with food expenditures at or below the food poverty line established by the Bangladesh Bureau of Statistics. Alarmingly, this number includes 266500 extreme poor, whose total expenditures are at or below the food poverty line. All five sub-districts are poor by national standards; their national percentiles vary from 71.5 to 92.3 for extreme poverty and 77.0 to 91.0 for poverty (World Bank 2014).

We assess the implication of projected mangrove migration for the five sub-districts by computing changes at the sub-district level for 27 climate scenarios. Table 4 summarizes the results for five dominant mangrove species. Here it is worth noting that all five sub-districts in the region are poor by national standards, but Shyamnagar and Koyra are the poorest and most populous. For Heritiera fomes (Sundri), the most valuable species overall, the negative impact is concentrated in Koyra, with a median decline of $58.0 \%$. However, this is at least partly offset by significant increases in Avicennia alba, A. marina, A. officinalis (Baen) (45.6\%), Excoecaria agallocha (Gewa)

\footnotetext{
${ }^{9}$ It should be noted that there are other significant stresses on Heritiera fomes in Sundarbans unrelated to salinity. For example, since around 1970, "top-dying disease" or crown-death of millions of Heritiera fomes trees in Sundarbans has led to significant economic losses and the losses are likely to continue in the future (Rahman 1990; Rahman 1995; Iftekhar and Islam 2004; Giri et al. 2007; Awal 2014).
}

(20.0\%) and Ceriops decandra (Goran) (20.0\%). In contrast, Shyamnagar has very large declines in Avicennia alba, A. marina, A. officinalis (Baen) (71.0\%), Excoecaria agallocha (Gewa) (67.3\%) and Sonneratia apetala (Keora) $(68.1 \%)$ with negligible offsetting gains for other valuable species. Overall, the disproportionate losses of Heritiera fomes (Sundri) in Koyra and three key species in Shyamnagar indicate that salinity-induced mangrove migration will have a strongly regressive impact on the value of standing timber stocks in the region.

Our results also suggest some potentially countervailing effects. For example, many poor households collect honey ${ }^{10}$ and wax during the summer season from March to June (Chakrabarti 1987; Krishnamurty 1990). Field research has indicated that among the various mangrove species, honey bees in the Sundarbans prefer Excoecaria agallocha (Gewa), Avicennia alba, A. marina, A. officinalis (Baen), Ceriops decandra (Goran), Heritiera fomes (Sundri), Sonneratia apetala (Keora) and Bruguiera gymnorrhiza (Kankra) (Chakrabarti 1987). ${ }^{11}$ Hence, the change in

\footnotetext{
${ }_{10}$ According to experts in Bangladesh, potential honey production is between 3000 and 5000 tons per annum if the potential is fully exploited. At present, the price is Tk. 125 to Tk. 135 per kg for honey collected from the Sundarbans with rudimentary sieving. The estimated total value of honey production from the Sundarbans is between Tk. 375 million and Tk. 675 million per annum if the full potential of honey production is exploited.

${ }^{11}$ In the Sundarbans, bees display the following preference percentages for making honeycombs: Excoecaria agallocha (Gewa) (39\%), Avicennia alba, A. marina, A. officinalis (Baen) (16\%), Ceriops decandra (Goran) (11\%), Garjan (10\%), Heritiera fomes (Sundri) (9\%), Sonneratia apetala (keora) $(5 \%)$, and Bruguiera gymnorrhiza (Kankra) (4\%). See Chakrabari (1987).
} 
mangrove species in favor of Avicennia alba, A. marina, A. officinalis (Baen), Excoecaria agallocha (Gewa), Ceriops decandra (Goran), and Sonneratia apetala (Keora) is likely to increase overall honey production. However, the impacts will not be evenly distributed across sub-districts. Table 4 suggests that the poorest sub-district, Shyamnagar, will experience significant declines in honey production from Avicennia alba, A. marina, A. officinalis (Baen), Excoecaria agallocha (Gewa), and Sonneratia apetala (Keora). On the other hand, Koyra will benefit from an increase in Avicennia alba, A. marina, A. officinalis (Baen), Excoecaria agallocha (Gewa), and Ceriops decandra (Goran), and Mongla will benefit from an increase in $E x$ coecaria agallocha (Gewa).

While increased honey collection overall can be beneficial for forest-based livelihoods in the neighboring region, we should stress that this activity is fraught with hazards from twice-daily tidal inundations and attacks by maneating tigers, crocodiles, venomous snakes and sharks. The available statistics indicate that thousands of honey collectors have been killed by tigers, crocodiles and snakes since human habitation of the Sundarbans began. It is believed that approximately 80 people are killed every year by tigers alone. Therefore, augmented production of honey, unless properly managed, is likely to increase conflicts between humans and wildlife.

\section{SUMMARY AND CONCLUSIONS}

In this paper, we have used a detailed scenario analysis to assess possible impacts of climate change, sea level rise and land subsidence on aquatic salinity, mangrove species migration and poor communities in the Bangladesh Sundarbans. Our analysis draws on spatially formatted information from Dasgupta et al. (2015a), including aquatic salinity in 2012 and 27 projections for 2050, developed from combinations of three IPCC climate change scenarios (B1, A1B, A2); three global circulation models (IPSLCM4, MIROC3.2, ECHO-G); and three assumptions about the rate of subsidence in the Ganges Delta $(2,5$ and $9 \mathrm{~mm} /$ year).

Our results cover salinity-induced migration patterns for 14 mangrove types: both sole species-Avicennia alba, A. marina, A. officinalis (Baen), Excoecaria agallocha (Gewa), Ceriops decandra (Goran), Bruguiera gymnorrhiza (Kankra), Sonneratia apetala (Keora), Xylocarpus mekongensis (Passur), Heritiera fomes (Sundri)—and combinations of those species.

Using the most recent digital maps of aquatic salinity and mangrove distributions, we estimate incidence probabilities by unit salinity interval for each mangrove type. Then we combine estimated incidence probabilities with information on current species locations and our 27 salinity scenarios to project the distribution of mangrove types in 2050. We find significant overall losses for Heritiera fomes (Sundri) and Xylocarpus mekongensis (Passur) Bruguiera gymnorrhiza (Kankra), along with substantial gains for Excoecaria agallocha (Gewa), Excoecaria agallocha (Gewa) Ceriops decandra (Goran) and Xylocarpus mekongensis (Passur) Bruguiera gymnorrhiza (Kankra) Avicennia alba, A. marina, A. officinalis (Baen). Projected gains are modest for Ceriops decandra (Goran) and Ceriops decandra (Goran) Excoecaria agallocha (Gewa).

We overlay the results with an administrative map of the Sundarbans region and compute changes in mangrove types for the five sub-districts in the region. We find highly varied patterns of gain and loss for the 14 mangrove types across the five sub-districts, with particularly interesting results for five species that have significant economic and ecological value: Heritiera fomes (Sundri), Avicennia alba, A. marina, A. officinalis (Baen), Excoecaria agallocha (Gewa), Ceriops decandra (Goran) and Sonneratia apetala (Keora). For Heritiera fomes (Sundri), the most valuable species overall, the negative impact is concentrated in Koyra, with a median decline of $58.0 \%$. However, this is at least partly offset by significant increases in Avicennia alba, A. marina, A. officinalis (Baen), Excoecaria agallocha (Gewa), and Ceriops decandra (Goran). In contrast, Shyamnagar has very large declines in Avicennia alba, A. marina, A. officinalis (Baen), Excoecaria agallocha (Gewa), and Sonneratia apetala (Keora), with negligible offsetting gains in other valuable species. In summary, our results suggest that migration of mangrove species driven by aquatic salinization will have the greatest negative impacts on the poorest sub-districts via loss of standing timber value and honey production, as well as increased risk of human-wildlife conflicts.

It should be noted that despite the widely acknowledged, treaty-protected ecological status of the Sundarbans, concerns related to growing aquatic salinity have not yet been incorporated into regional management protocols. Over time, eastward meandering of the Ganges and Brahmaputra is reducing freshwater inflows significantly. At present, the water from the Ganges which flows through its distributary, the Gorai River, is the only major source of freshwater for the Sundarbans. The Gorai is almost empty during the dry season (December-May), and tidal effects cause intrusion of saline water through several major rivers-the Baleswar, Jamuna, lower Meghna, Malancha, Pussur, Sibsa, and Tnetulia. The region is very flat, so strong tidal effects at times travel up to $200 \mathrm{~km}$ upstream, even at the current sea level. These effects will be exacerbated by continuing sea level rise. As long as such dynamics continue, efforts to improve local ecological conditions through hydrological regime changes (e.g., river training and other engineering 
work) will probably be futile (Potkin 2004). Hence, engineering attempts to control rising salinity in the Sundarbans do not seem likely to succeed.

The Sundarbans is a UNESCO World Heritage Site, internationally recognized under the Ramsar Convention. Effective conservation management of the Sundarbans will require establishment of location-specific baseline data for tree stand structures, tree abundance, species richness and diversity, the export of nutrients, hydrological patterns, rates of sedimentation and relative sea-level rise (see McLeod and Salm (2006) in the IUCN-Nature Conservancy Report on Managing Mangroves for Resilience to Climate Change). Such baseline data will permit monitoring of changes in the Sundarbans mangrove systems over time. Since mangroves depend on fluxes of both daily tides and fresher water, management protocols should include both connectivity between mangrove systems and nearby river sources, and maintenance of upland freshwater catchments. Areas that are likely to survive sea level rise in a changing climate should be identified (See Dasgupta et al. 2016b for a methodology). Tidal fluctuations, varying $\mathrm{pH}$ and salinity should be monitored, to support additional planting of suitable mangrove species where necessary. Attempts to restore mangrove areas that are currently degraded should also be undertaken.

Since changes in mangrove stocks induced by rising aquatic salinity are likely to change the prospects for forest-based livelihoods, resources should also be directed to the development of alternative livelihoods for mangrovedependent households.

Worldwide, low-lying coastal regions will be at increasing risk from inundation, salinization and other potential impacts because sea level rise will continue beyond 2100 even if greenhouse gas emissions are stabilized in the near future. ${ }^{12}$ Impacts on globally important mangrove ecosystems and the socioeconomic implications will undoubtedly be an important part of this story. Unfortunately, our knowledge remains far from complete and such assessment deserves further analyses. This paper represents an attempt to narrow the knowledge gap for coastal Bangladesh with local high-resolution spatial data. We hope that analyses such as this one will promote more widespread efforts to develop conservation and sustainable development policies that incorporate rising salinity, changes in mangrove dynamics, and their impacts on the welfare of neighboring communities.

\footnotetext{
12 Recent research suggests that the sea level may rise by one meter or more in the twenty-first century, which would increase the vulnerable population to about one billion by 2050 (Rahmstorf 2007; Pfeffer et al. 2008; Dasgupta et al. 2009; Vermeer and Rahmstorf 2009; Hansen and Sato 2011; Brecht et al. 2012).
}

\section{Highlights}

- Climate change will drive progressive river salinization in the low-lying coastal areas of Bangladesh.

- Projection of river salinity permits estimation of the migration of mangrove species in the UNESCO Heritage Sundarbans through 2050.

- River salinization will significantly reduce the highestvalue timber species, Heritiera fomes.

- A significant increase is expected for Excoecaria agallocha, along with modest changes for Avicennia alba, A. marina, A. officinalis, Ceriops decandra, and Sonneratia apetala.

- Augmented potential for honey production will likely increase conflicts between humans and wildlife.

Acknowledgements The authors are grateful to Zahir Iqbal, Bangladesh Forest Department, for data on mangrove species in the Sundarbans. The authors are thankful to Yunus Ali, Chief Conservator of Forest, Bangladesh Forest Department, for his expert opinion. The authors would like to extend their special thanks to Lia Sieghart, Glenn-Marie Lange, Mainul Huq, and Michael Toman for their review comments on this paper. The authors also acknowledge help from Polly Means with the graphics.

Disclaimer The findings, interpretations, and conclusions expressed in this paper are entirely those of the authors. They do not necessarily represent the views of the International Bank for Reconstruction and Development/World Bank and its affiliated organizations, or those of the Executive Directors of the World Bank or the governments they represent.

\section{REFERENCES}

Aerts, L.J., A. Hassan, H. Savenije, and M. Khan. 2000. Using GIS tools and rapid assessment techniques for determining salt intrusion: STREAM - a river basin management instrument. Physics and Chemistry of the Earth, Part B: Hydrology, Oceans and Atmosphere 25: 265-273.

Agarwala, S., T. Ota, A.U. Ahmed, J. Smith, and M. van Aalst. 2003. Development and climate change in Bangladesh: Focus on the coastal flooding and the Sundarbans. Paris: OECD.

Alongi, D. 2008. Mangrove forests: Resiliance, protection from tsunamis and responses to global climate change. Estuarine, Coastal and Shelf Science 76: 1-13.

Alongi, D.M. 2002. Present state and future of the world's mangrove forests. Environmental Conservation 29: 331-349.

Awal, M.A. 2014. Analysis of causes of disease in Sundarbans natural mangrove. American Journal of Bioscience and Bioengineering 2: $18-32$.

Aziz, Abdul, and Ashit Ranjan Paul. 2015. Bangladesh Sundarbans: Present status of the environment and biota. Diversity 2015 7: 242-269.

Bhuiyan, M.J.A.N., and Dushmanta Dutta. 2011. Assessing impacts of sea level rise on river salinity in the Gorai river network, Bangladesh. Estuarine, Coastal and Shelf Science 96: 219-227.

Blasco, F., and M. Aizpuru. 2002. Mangroves along the coastal stretch of the Bay of Bengal: Present status. Indian Journal of Marine Sciences 31: 9-20. 
Brecht, H., S. Dasgupta, B. Laplante, S. Murray, and D. Wheeler. 2012. Sea-level rise and storm surges: High stakes for a small number of developing countries. The Journal of Environment \& Development 21: 120-138.

Chaffey D.R., F.R. Miller, and J.H. Sandom. 1985. A Forest inventory of Sundarbans, Bangladesh. Overseas Development Administration, Land Resources Development Centre, Surrey, England: 187.

Chakrabarti, K. 1987. Sundarbans honey and the mangrove swamps. Journal of Bombay Natural History Society 1: 133-137.

Dasgupta, S., B. Laplante, C. Meisner, D. Wheeler, and J. Yan. 2009. The impact of sea level rise on developing countries: A comparative analysis. Climatic Change 93: 379-388.

Dasgupta, S., M. Huq, Z.H. Khan, M.M.Z. Ahmed, N. Mukherjee, M.F. Khan, and K. Pandey. 2014a. Vulnerability of Bangladesh to cyclones in a changing climate: Potential damages and adaptation cost. Climate and Development 6: 96-110.

Dasgupta, S., M.M. Hossain, M. Huq, and D. Wheeler. 2014b. Climate change, soil salinity and the economics of high-yield rice production in coastal Bangladesh. Policy Research Working Paper \# 7140. Development Research Group, World Bank.

Dasgupta, S., M. Huq, and D. Wheeler. 2014c. Facing the hungry tide: Climate change, livelihood threats and household responses in coastal Bangladesh. Policy Research Working Paper (forthcoming), Development Research Group, World Bank.

Dasgupta, S., M.M. Hossain, M. Huq, and D. Wheeler. 2015a. Climate change and soil salinity: The case of coastal Bangladesh. Ambio 44: 815-826.

Dasgupta, S., M. Huq, and D. Wheeler. 2015b. Climate change, soil salinity and road maintenance costs in coastal Bangladesh. Water Economics and Policy 1. http://www.worldscientific.com/doi/ pdf/10.1142/S2382624X15500174?src=recsys.

Dasgupta, S., M. Huq, and D. Wheeler. 2015c. Drinking water salinity and infant mortality in coastal Bangladesh. Policy Research Working Paper. Forthcoming in Water Economics and Policy 1. http://www.worldscientific.com/doi/pdf/10.1142/S2382624X165 0003X? src=recsys.

Dasgupta, S., M. Huq, M.G. Mustafa, I. Sobhan, and D. Wheeler. 2016a. The impact of climate change and aquatic salinization on fish species and poor communities in the Bangladesh Sundarbans. World Bank Policy Research Working Paper \# 7593.

Dasgupta, S., M. Huq, I. Sobhan, and D. Wheeler. 2016b. Species conservation indicators for Bangladesh's Sundarbans region. World Bank Policy Research Working Paper (forthcoming), April.

Ellison, J.C., and D.R. Stoddart. 1991. Mangrove ecosystem collapse during predicted sea level rise; holocene analogues and implications. Journal of Coastal Research 7: 151-165.

Erwin, K.L. 2009. Wetlands and global climate change: The role of wetland restoration in a changing world. Wetlands Ecology and Management 17: 71-84.

Gilman, E., H. Van Lavieren, J.C. Ellison, V. Jungblut, L. Wilson, F. Areki, G. Brighouse, J. Bungitak, et al. 2006. Pacific island mangroves in a changing climate and rising sea. Nairobi: United Nations Environment Programme, Regional Seas Programme, Regional Seas Report and Studies No. 179.

Giri, C., B. Pengra, Z. Zhu, A. Singh, and L.L. Tieszen. 2007. Monitoring mangrove forest dynamics of the Sundarbans in Bangladesh and India using multi-temporal satellite data from 1973 to 2000*. Estuarine, Coastal and Shelf Science 73: 91-100.

Gopal, B., and M. Chauhan. 2006. Biodiversity and its conservation in the Sundarban mangrove ecosystem. Aquatic Sciences 68: $338-354$

Government of Bangladesh (GoB). 2010. Integrated resources management plans for the Sundarbans (2010-2020), vol. 1. Forest Department. Ministry of Environment and Forests, December 2010.
Hansen, J.E., and M. Sato. 2011. Paleoclimate implications for human-made climate change. NASA Goddard Institute for Space Studies and Columbia University Earth Institute.

Hassan, A., and MdAR Shah. 2006. Impact of sea level rise on suitability of agriculture and fisheries. Dhaka: Center for Environmental and Geographic Information Services.

Hoque, M.A., M.S.K.A. Sarkar, S.A.K.U. Khan, M.A.H. Moral, and A.K.M. Khuurram. 2006. Present status of salinity rise in Sundarbans area and its effect on Sundari (Heritiera fomes) species. Research Journal of Agriculture and Biological Sciences 2: 115-121.

Hussain, Z., and G. Acharya. 1994. Mangroves of the Sundarbans, vol. 2. The IUCN Wetlands Programme Report. https://portals. iucn.org/library/node/6855.

Iftekhar, M.S., and M.R. Islam. 2004. Managing mangroves in Bangladesh: A strategy analysis. Journal of Coastal Conservation 10: 139-2004.

IPAC. 2010. A study of the principal marketed value chains derived from the Sundarbans reserved forest, integrated protected area co-management (IPAC) project. Washington, DC: International Resources Group.

IWM. 2003. Sundarban biodiversity conservation project: Surface water modeling. Final Report. Institute of Water Modeling, Ministry of Environment and Forests, Government of Bangladesh.

Karim, Z., S.G. Hussain, and M. Ahmed. 1990. Salinity problems and crop intensification in the coastal regions of Bangladesh. Soils publication No. 33. Bangladesh Agricultural Research Council.

Krishnamurty, K. 1990. The apiary of the mangroves. In Wetland ecology and management: Case studies, ed. D.F. Whigham, D. Dykyjova, and S. Hejny, 135-140. Dordrecht: Kluwer Academic Publishers.

Lange, G.-M., S. Dasgupta, T. Thomas, S. Murray, B. Blankespoor, K. Sander, and T. Essam. 2010. Economics of adaptation to climate change-ecosystem services. The World Bank Discussion Paper No. 7.

Mcleod, E., and R.V. Salm. 2006. Managing mangroves for resilience to climate change, 64. Gland: IUCN.

Mukhopadhyay, A., P. Mondal, J. Barik, S.M. Chowdhury, T. Ghosha, and S. Hazraa. 2015. Changes in mangrove species assemblages and future prediction of the Bangladesh Sundarbans using Markov chain model and cellular automata. Royal Society of Chemistry: Environmental Science Processes \& Impacts, February.

Nobi, N., and A.D. Gupta. 1997. Simulation of regional flow and salinity intrusion in an integrated stream-aquifer system in coastal region: Southwest region of Bangladesh. Ground Water 35: 786-796.

Petersen, L., and S. Shireen. 2001. Soil and water salinity in the coastal area of Bangladesh. Bangladesh Soil Resource Development Institute.

Pfeffer, W.T., J.T. Harper, and S. O'Neel. 2008. Kinematic constraints on glacier contributions to 21 st-century sea-level rise. Science 321: 1340-1343.

Potkin, A. 2004. Watering the Bangladesh Sundarbans. In The Ganges water dispersion: Environmental effects and implications, ed. M.M.Q. Mirza, 163-176. Dordrecht: Kluwer Academic Publishers.

Rahman, M.A. 1990. A Comprehensive report on sundry (Heritiera fomes) trees with particular reference to top dying in Sundarbans. In Proceedings of the seminar on top dying of Sundri (Heritiera fomes) trees, ed. M.A. Rahman, M.A. Khandakar, F.U. Ahmed, and M.O. Ali, 256. Dhaka: Bangladesh Agricultural Research Council.

Rahman, M.A. 1995. Mangrove plant pathology of the Sundarbans reserved forest in Bangladesh. Field Document Note 3 of FAO/ 
UNDP project BGD/84/056 Integrated Resource Development of the Sundarbans Reserve Forest. Forest Department, Khulna, Bangladesh.

Rahmstorf, S. 2007. A semi-empirical approach to projecting future sea-level rise. Science 315: 368-370.

Semeniuk, V. 1994. Predicting the effect of sea level rise on mangroves in Northwestern Australia. Journal of Coastal Research 10: 1050-1076.

SRDI. 2000. Soil salinity in Bangladesh 2000. Dhaka: Soil Resources Development Institute.

SRDI. 2010. Saline soils of Bangladesh. Dhaka: Soil Resources Development Institute.

Uddin, M.S., M.A.R. Shah, S. Khanom, and M.K. Nesha. 2013. Climate change impacts on the Sundarbans mangrove ecosystem services and dependent livelihoods in Bangladesh. Asian Journal of Conservation Biology 2: 152-156.

UK DEFR (U.K. Department of Environment, Food and Rural Affairs). 2007. Investigating the impact of relative sea-level rise on coastal communities and their livelihoods in Bangladesh. Dhaka: Institute of Water Modelling in Bangladesh and Center for Environment and Geographic Information Services in Bangladesh.

UNEP. 1994. Assessment and Monitoring of climate change impacts on mangrove ecosystems. UNEP Regional Seas Reports and Studies No. 154. UNEP, Nairobi.

Vermeer, M., and S. Rahmstorf. 2009. Global sea level linked to global temperature. Proceedings of the National Academy of Sciences 106: 21527-21532.

World Bank. 2000. Bangladesh: Climate change and sustainable development. Report No. 21104-BD. Rural Development Unit, South Asia Region. December.

World Bank. 2014. Bangladesh poverty map 2010. Dhaka: World Bank, Bangladesh Bureau of Statistics, World Food Programme.

\section{AUTHOR BIOGRAPHIES}

Susmita Dasgupta $(\square)$ is Lead Environmental Economist in the World Bank's Development Research Group. She is a specialist in the empirical research in environmental economics and has done extensive research on pollution control, poverty/environment nexus, and climate change.

Address: Development Research Group, The World Bank, $1818 \mathrm{H}$ Street, Washington, DC 20433, USA.

e-mail: sdasgupta@worldbank.org

Istiak Sobhan is an Environmental Specialist in the World Bank country office in Bangladesh. He contributes to the World Bank dialogue on forests, (fisheries, coasts, oceans in South Asia. Before joining the World Bank, he was a Program coordinator in IUCN, International Conservation Union, Bangladesh Country and also is Director, Center for Environmental and Geographic Information Services (CEGIS).

Address: The World Bank, E-32, Agargaon, Sher-e-Bangla Nagar, Dhaka 1207, Bangladesh.

e-mail: Istiak.sobhan@yahoo.com

David Wheeler is a Senior Fellow in the World Resources Institute. His research interests include climate change, natural resource conservation, public disclosure of pollution, sustainable development indicators, human resource development, African infrastructure development.

Address: World Resources Institute, 10 G Street NE \#800, Washington, DC 20002, USA.

e-mail: wheelrdr@gmail.com 